\title{
Venöz tromboembolizm risk faktörlerinin değerlendirilmesi
}

\section{Evaluation of the risk factors of venous thromboembolism}

\author{
Aykut Koçyiğit ${ }^{1}$, Bülent Atilla ${ }^{2}$ \\ ${ }^{1}$ Polatlı Devlet Hastanesi, Ortopedi ve Travmatoloji Kliniği, Ankara \\ ${ }^{2}$ Hacettepe Üniversitesi Tıp Fakültesi, Ortopedi ve Travmatoloji Anabilim Dalı, Ankara
}

\begin{abstract}
Venöz tromboemboli, (VTE) derin ven trombozu (DVT) ve pulmoner tromboembolizm (PTE) hastalıklarını da içeren, yıllık insidansı erişkin popülasyonda $\% 0,1-0,3$ olan potansiyel ölümcül bir hastalıktır. Tanı konulduktan sonra bir ay içinde ölüm oranı DVT hastalarında \%6, PTE hastalarında \%12'dir. Bu nedenle VTE, önlem alınmazsa, hastane morbidite ve mortalitesinin en önemli nedenidir. Majör ortopedik cerrahi sonrasında profilaksi uygulanmayan hastalarda \%40-60 oranında DVT ortaya çıkmaktadır. VTE ve tekrarlayan VTE için birçok risk faktörü vardır. Hastanede yatan hastaların çoğu VTE açısından en az bir risk faktörüne sahipken, bu hastaların \%40'ı üç veya daha fazla risk faktörü taşımaktadır. Majör ortopedik cerrahiler olarak bilinen kalça kırıkları, diz ve kalça artroplastileri yüksek VTE riskine sahiptir. Majör ortopedik cerrahiler yanında, hastaya özel (yaş, kilo, sigara, genetik trombofililer, VTE öyküsü gibi) bilinen ek klinik riskler bulunabilir. Bu nedenle, VTE ve kanama risk analizi her hasta için ayrı ayrı yapılmalıdır. Risk faktörlerinin değerlendirilmesinde çeşitli skorlama yöntemleri ve kılavuzlar bize yol gösterebilir. DVT ve fatal olan pulmoner emboliden korunmanın yolu, hastaların VTE risk faktörleri ve kanama riskleri açısından iyi değerlendirilmesi sonucunda hastaya özgü profilaksi tedavisinin uygulanmasından geçer.
\end{abstract}

Anahtar sözcükler: tromboembolizm; venöz tromboembolizm; pulmoner emboli; risk faktörleri
Venous thromboembolism (VTE) is a potential fatal disease with an annual incidence of $0.1-0.3 \%$ in the adult population, including deep vein thrombosis (DVT) and pulmonary thromboembolism (PTE). The mortality rate within 1 month is $6 \%$ for DVT patients and $12 \%$ for PTE patients after diagnosis. Therefore, VTE is the most important cause of hospital morbidity and mortality if no measures are taken. DVT occurs in $40 \%$ to $60 \%$ of patients without prophylaxis after major orthopedic surgery. There are many risk factors for VTE and recurrent VTE. While most hospitalized patients have at least one risk factor for VTE, $40 \%$ of these patients have three or more risk factors. Hip fractures, knee and hip arthroplasties, known as major orthopedic surgeries, have a high risk of VTE. In addition to major orthopedic surgeries, there may be additional clinical risks identified for a specific patient (age, weight, smoking, genetic thrombophilias, VTE history). Therefore, VTE and bleeding risk analysis should be performed separately for each patient. Various scoring methods and guidelines can guide us in the evaluation of risk factors. The way of protection from DVT and fatal pulmonary embolism is through the application of patient-specific prophylaxis treatment as a result of good evaluation of patients with VTE risk factors and bleeding risks.

Key words: thromboembolism; venous thromboembolism; pulmonary embolism; risk factors
$\mathbf{V}$ enöz tromboembolizmin (VTE) nedeni, çoğunlukla bacak derin venlerinde oluşan trombüslerdir. Bu trombüslerden bir kısmı koparak dolaşım yolu ile akciğerlere gelir ve pulmoner tromboembolizme yol açar. Venöz tromboemboli (VTE) derin ven trombozu (DVT) ve pulmoner tromboembolizm (PTE) hastalıklarını da içeren, yıllık insidansı erişkin popülasyonda \%0,1-0,3 olan potansiyel fatal bir hastalıktır. ${ }^{[1]}$ Akut dahiliye ve cerrahi hastalarında sık görülen bir komplikasyondur. ${ }^{[2,3]}$ Hastane ölümlerinin yaklaşık \%10'u PTE'ye bağlıdır. ${ }^{[3]}$ Hastaneye yatanlarda fatal PTE görülme sıklığı, elektif genel cerrahi operasyonu sonrası $\% 0,1-0,8$, elektif kalça protezi sonrası \%2-3, kalça kırığına yönelik cerrahi sonrası ise $\% 4-7$ 'dir. ${ }^{[4]}$

Tanı konulduktan sonra bir ay içinde ölüm oranı DVT hastalarında \%6, PTE hastalarında \%12'dir. ${ }^{\left[{ }^{[]}\right.} \mathrm{Bu}$ nedenle VTE, önlem alınmazsa, hastane morbidite ve mortalitesinin en önemli nedenidir. ${ }^{[6-8]}$ VTE riski, gerek cerrahi kliniklerde gerekse dahili kliniklerde bilinmesine

- Illetişim adresi: Dr. Bülent Atilla, Hacettepe Üniversitesi Tıp Fakültesi, Ortopedi ve Travmatoloji Anabilim Dalı, 06100 Sıhhiye, Ankara Tel: 0532 - 2928717 e-posta: batilla@gmail.com

- Geliş tarihi: 22 Șubat 2019 Kabul tarihi: 6 Ağustos 2019 
rağmen, profilaksi uygulama oranları istenilen düzeyde değildir. ENDORSE (Epidemiologic International Day for the Evaluation of Patients at Risk for Venous Tromboembolism in the Acute Hospital Care Setting) çalışması, çok uluslu ve ülkemizden de 11 merkezin katılımılla gerçekleşen bir araştırmadır. Bu araştırmanın sonuçlarına göre, VTE riski taşıyan cerrahi olgusunun \%58'ine, medikal hasta grubunun ise yalnızca \%39,5'ine profilaksi uygulandığı gösterilmiştir. ${ }^{[2]}$ Venöz tromboembolizm; mortalite, morbidite ve sağlık harcaması yüksek olan, ancak önlenebilir bir hastalıktır.

Hastanede yatan hastaların çoğu VTE açısından en az bir risk faktörüne sahipken, bu hastaların \%40'ı üç veya daha fazla risk faktörü taşımaktadır. Tromboprofilaksi (TP) uygulanmayan medikal veya cerrahi hastalarında DVT oranı yaklaşık \%10-40'dır. Majör ortopedik cerrahi sonrasında profilaksi uygulanmayanların \%40-60'ında DVT ortaya çıkar. ${ }^{[6,9]}$

Ortopedi ve travmatolojide majör ortopedik cerrahi olarak anılan total kalça protezi (TKP), total diz protezi (TDP) ve kalça kırığı sık yapılan ameliyatlardır. Bu grup hastaların ameliyatlarından sonra görülen komplikasyonlardan biri de venöz tromboembolidir.[10] Profilaksi yapılmaz ise, TKP ameliyatı sonrası \%45-57, TDP sonrası \%41-85, kalça kırı̆̆ı sonrası \%46-60 oranında DVT görülür..$^{[4,11]}$ Koruyucu etkisi kanıtlanmış olmasına karşın TP dünyada ve ülkemizde ne yazık ki çoğunlukla ihmal edilmektedir. Günümüzde, VTE için orta-yüksek düzeyde risk taşıyan hastaların bile, dünya genelinde \%50'si, Türkiye'de ise \%61'i optimal profilaksiden yoksun bırakılmaktadırlar. ${ }^{[2,12]}$

1884'de tanımlanmış olan Virchow'un triadındaki patofizyolojik süreçlerin (vasküler endoteliyal hasar, staz, hiperkoagülabilite) yokluğunda VTE genellikle gelişmez. Opere olan ortopedi hastasında ise bu patofizyolojik olayların hepsi mevcuttur. 1) Turnike kullanımı, immobilizasyon ve yatak istirahati staza neden olur. 2) Ekstremitenin cerrahi manipülasyonu vasküler endoteliyal hasara neden olur. 3) Travma tromplastin ajanları arttırır. 4) Kemik çimentosu polimetilmetakrilat (PMMA) kullanımı hiperkoagülabiteyi arttırır. Bu nedenle, ortopedik cerrahi geçiren ve ortopedik travmalı hastalarda, risk faktörlerinin iyi değerlendirilmesi ve VTE profilaksisi ile ilgili kılavuzlara uyulması çok önemlidir.

\section{VTE RISK FAKTÖRLERi}

VTE ve tekrarlayan VTE için birçok risk faktörü vardır. Ülkemizde yapılan bir çalışmada, majör ortopedik cerrahiler olarak bilinen TKP, TDP ve kalça kırığı ameliyatı uygulanan hastaların \%73,2'sinde VTE risk faktörleri saptanmıştır. Bu risk faktörleri; TKP'de \%60,4, TDP'de \%75,3 ve kalça kırığında \%86,3 olarak görülmüştür. ${ }^{[1]]}$ Majör ortopedik cerrahilerde en sık görülen risk faktörleri; obezite, uzamış immobilizasyon, sigara içme ve venöz yetmezliktir. ${ }^{[11]}$ Majör ortopedik cerrahiler yanında, hastanın kendisine ait (yaş, kilo, sigara, genetik trombofililer, VTE öyküsü gibi) tanımlanmış ek klinik riskler Tablo 1'de gösterilmiştir. ${ }^{[13]}$ Bu riskleri

Tablo 1. Venöz tromboembolizm risk faktörleri

- Aktif kanser ya da kanser tedavisi uygulanıyor olmak.

- Altmış yaş ve üstünde olmak.

- Uzun süre immobilizasyon (>72 saat).

- Sigara içmek.

- Inflamatuvar hastalık.

- Yoğun bakım hastası olmak.

- Dehidratasyon.

- Bilinen trombofilik hastalık.

- Obezite (vücut kitle indeksinin $30 \mathrm{~kg} / \mathrm{m}^{2}$ 'den fazla olması).

- Hastada ya da birinci dereceden yakınında geçirilmiş VTE öyküsünün olması.

- Hormon replasman tedavisi alıyor olmak.

- Östrojen içeren doğum kontrol ilacı kullanıyor olmak.

- Flebitli variköz venlerin bulunması, venöz yetmezlik.

- Bir ya da daha fazla önemli komorbiditenin bulunması (kronik kalp hastalığı; metabolik, endokrin ya da solunumsal hastalıklar; akut enfeksiyonlar; inflamatuvar hastalıklar).

- Hamilelik ya da altı hafta içinde doğum yapmış olmak.

- Ortopedik cerrahi (total kalça protezi, total diz protezi ve kalça kırığı hastaları) varlığı.

- Non-ortopedik cerrahi (genel cerrahi, abdominal, jinekolojik, toraks, ürogenital, travma ve kanser cerrahisi) hastası olmak. 
taşıyan hastalarda, VTE oluşmadan, mekanik ya da farmakolojik yöntemlerle yapılan koruyucu tedaviye (birincil koruma) TP denir.

İmmobilizasyon, en az üç gün süre ile yatağa bağımlılık, ya da zamanının büyük bir kısmını, yatarak ya da oturarak geçirmek durumunda olmak olarak tanımlanır. ${ }^{[14]}$ VTE'nin gelişiminde immobilizasyonun önemi vurgulanmaktadır. ${ }^{[15]}$ Benzer şekilde, erken yük vermeye ve harekete izin verilen total diz artroplastisi hastalarında, D-dimer düzeylerinin anlamlı şekilde düşük olduğu gözlenmiştir. ${ }^{[15,16]}$ Hastanede yatmakta olan tüm immobil hastalar, VTE riski açısından değerlendirilmeli ve kontrendikasyon yoksa, özellikle riskin yüksek olduğu hastalarda, profilaksi tedavisine başlanmalıdır (Tablo 2). Profilaksi yönteminin seçiminde, VTE risk düzeyi, hastanın klinik koşulları, kanama riski, seçilecek yöntemin komplikasyonları, hastanın tercihi ve hastanın yönteme uyumu dikkate alınmalıdır. Farmakolojik TP yapılacak olan hastalar, profilaksi başlamadan önce, özellikle kanama riski açısından da değerlendirilmelidir. TP sırasında kanama riskini arttıracak klinik durumlar olabilir (Tablo 3). ${ }^{[13,17]}$ Ayrıca ileri yaş (75 yaş üstü), aktif kanser ve TP süresinin uzaması, kanama riskini arttıran önemli nedenlerdir. ${ }^{[18,19]}$ Tablo 3 'te gösterilmiş olan risklerden birini taşıyan hastada, TP farmakolojik ajanlarla yapılmamalı, mekanik yöntemlere başvurulmalıdır. Ancak, mekanik yöntemlerin yetersiz kaldığı ya da kalacağı düşünülen hastalarda kullanılacak yönteme, VTE riski ve kanama riski birlikte değerlendirilerek karar verilmelidir.
Yapılan çalışmalara göre, majör ortopedik cerrahi sonrası VTE profilaksisi almamış olan hastalarda venografik olarak dokümante edilmiş DVT ve proksimal DVT oranları, sırasıyla \%40-60 ve \%10-30'dur. ${ }^{[4]} \mathrm{Bu}$ hastalar, hastaneden taburcu olduktan sonra da risk altındadır. Kalça kırığı cerrahisinden sonra venöz fonksiyon 42 güne kadar anlamlı şekilde bozuk olurken, hiperkoagülabilite kalça kırığından sonra altı hafta boyunca devam edebilir. ${ }^{[20,21]}$ VTE, total kalça ve diz artroplastisinden sonra üç aya kadar oluşabilir ve TKP sonrası tekrar hastaneye yatışların en sık nedenidir. ${ }^{[6,22]}$ Yapılan bir çalışmada, profilaksi uygulanmayan TKP hastalarının \%20'sinde, taburculuk esnasında negatif venogramı olmasına rağmen, tekrarlayan venograma dayanarak sonraki üç hafta içinde yeni DVT geliştiği saptanmıştır. ${ }^{[23]}$ DVT geçiren hastaların \%30'u, tanı ve tedaviden sonraki 8-10 yıl içinde tekrar VTE geçirebilir. ${ }^{[9,24]}$ Rutin VTE profilaksisi uygulanan hastalarda fatal pulmoner emboli (PE) sık değildir ve üç ay içinde semptomatik VTE oranı \%1,3-10'a inmektedir. ${ }^{[6]}$

Majör ortopedik cerrahide VTE profilaksisi için çeşitli makaleler ve ilgili kılavuzlar yayımlanmıştır. Günümüzde yayımlanmış, dünya çapında kullanılan kılavuzlar şunlardır: American College of Clinical Pharmacy (ACCP) (2012), American Association of Orthopaedic Surgery (AAOS) (2011), Scottish Intercollegiate Guidelines Network (SIGN) (2010, 2015'te güncellenmiştir) ve National Institute of Health and Care Excellence (NICE) (2018).

Tablo 2. Venöz tromboembolizm TP'sinde izlenecek yol

- Kırk yaş üstü tüm cerrahi ya da medikal hastaları, TP açısından değerlendir.

- Kanıtlanmış klinik VTE risklerinin varlığını araştır.

- Kanama riskini değerlendir.

- Kanama riski yok ve VTE riski orta-yüksekse farmakolojik TP yap.

- Kanama riski var ve VTE riski orta-yüksekse mekanik TP yap.

- Hastayı VTE, olası kanama riski ve TP komplikasyonları konusunda bilgilendir.

Tablo 3. Kanama riskini arttıran klinik durumlar

\footnotetext{
- Aktif kanama.

- Akut inme.

- Trombositopeni $\left(<75.000 / \mathrm{mm}^{3}\right)$.

- Edinsel kanama diyatezi varlığı (akut karaciğer yetersizliği (INR >1,5), böbrek yetersizliği $\left(G F R<30 \mathrm{~mL} / \mathrm{dk} / \mathrm{m}^{2}\right)$ ).

- Tedavisiz kalıtsal kanama diyatezinin olması (hemofili, von Willebrand hastalığı...).

- Eşzamanlı oral antikoagülan kullanımı.

- Son dört saat içinde yapılmış lomber ponksiyon, epidural/spinal anestezi.

- Gelecek 12 saat içinde yapılacak olan lomber ponksiyon, epidural/spinal anestezi.

- Kontrolsüz sistemik hipertansiyon (230/120 mmHg ve üstü).
} 
VTE için risk faktörlerini bu çalışma ve kılavuzlara göre değerlendirecek olursak;

SIGN (2010) [25]' a göre;

1) VTE için risk faktörleri; yaş, obezite, varikoz venler, VTE aile öyküsü, trombofililer, kombine oral kontraseptifler, hormon replasman tedavisi alanlar, anti-östrojen tedavi, gebelik, lohusalık, immobilizasyon, uzun süre immobil seyahat etmek, hastanede yatmak, anestezi ve santral venöz kateter takılmasıdır.

2) Rekürrens VTE için risk faktörleri; daha önceki nedeni bilinemeyen VTE, erkek cinsiyet, obezite ve trombofililerdir. ${ }^{[25]}$

Anderson ve ark.'na göre ${ }^{[10]}$;

1) VTE için kuvvetli risk faktörleri; kalça ve bacak kırıkları, diz ve kalça protezleri, majör genel ameliyatlar, majör travma ve spinal kord yaralanmalarıdır.

2) Orta risk faktörleri; artroskopik diz cerrahisi, santral venöz kateterler, kemoterapi, konjestif kalp yetmezliği, solunum yetmezliği, hormon replasman tedavisi, malignensi, oral kontraseptif uygulama, paralitik inme, gebelik/postpartum dönem, önceki VTE ve trombofilidir.

3) Zayıf risk faktörleri; üç günden fazla yatak istirahati, immobilizasyon, yatağa bağımlı bakım hastası olmak, artan yaş, laparoskopik cerrahi, obezite, gebelik/antepartum, varikoz venlerdir.

ACCP, hastanede yatan VTE profilaksisi uygulanmayan hastaları üç kategoriye ayırmıştı[ ${ }^{[6]}$ :

1. Düşük risk; tamamen mobil olan ve minör cerrahi geçiren ve mobil olan hastalarda risk \%10'dan azdır.

2. Orta risk; en sık genel cerrahi, açık jinekolojik ve ürolojik cerrahi geçiren hastalar ve yatalak medikal tedavi alan hastalar bu gruba girer ve bu hastalarda VTE riski \%10-40'tır.

3. Yüksek risk; kalça ve diz artroplastisi operasyonu geçiren, kalça kırığı olan, majör travma ve spinal kord yaralanması olan hastalardır.

ACCP, özellikle farmokolojik VTE profilaksisi uygulanacak ortopedik hastalar için uluslararası kılavuzlar arasında en kapsamlı ve uygun olanıdır. ${ }^{[26]}$

Nam ve ark. ${ }^{[27]}$ kalça artroplasti hastalarını yüksek riskli ve rutin risk grubu olarak ikiye ayırmışlardır. Yüksek riskli hastaların kriterleri: 70 yaş üstü, eski DVT öyküsü, kanser, hiperkoagülabilite, multipl komorbitite, vücut kitle indeksi (VKi) $40 \mathrm{~kg} / \mathrm{m}^{2}$, VTE aile öyküsü, uzamış immobilizasyondur. Rutin riskli 1402 hastaya aspirin ve pnömatik kompresyon cihazı kombine uygulanmıştır. Yüksek riskli 457 hastaya warfarin tedavisi verilmiştir. Altı haftada, eşit oranda $(\% 0,5)$ semptomatik VTE gelişmiştir. Ancak, rutin riskli hastalarda majör kanama ve yara yeri problemleri daha az görülmüştür. ${ }^{[27]}$

Gonzalez Della Valle ve ark. ${ }^{[28]}$ ile Vulcano ve ark. ${ }^{[29]}$, hastaları düşük risk, yüksek risk ve çok yüksek risk olarak üç gruba ayırmışlardır. Yüksek riskli hastaların kriterleri; obezite, yavaş mobilize olmak, bilateral TDP, bilinen malignensi veya hiperkoagülabilite durumu, yaşamı tehdit etmeyen VTE öyküsüdür. Çok yüksek riskli hastaların kriterleri; yaşamı tehdit eden VTE öyküsü veya multipl majör VTE olmasıdır. Düşük riskliler, daha önce bilinen risk faktörü olmayanlardan oluşmuştur. Düşük risk grubuna aspirin, yüksek risk grubuna warfarin ve çok yüksek risk grubuna DMAH (düşük molekül ağırlıklı heparin) ve warfarin profilaksisi verilmiştir. VTE oranları; düşük risk için $\% 1,1$, yüksek risk için $\% 1,5$ ve çok yüksek risk ise $\% 0$ saptanmış. Aspirin alanlarda kanama oranı $\% 0,3$, warfarin uygulananlarda \%1,6 olarak saptanmıştır.

\section{VTE PROFILAKSISINI KIMLERE VERELIM?}

VTE'de koruyucu tedavinin kimlere verilmesi gerektiği, bazı skorlama yöntemleri kullanılarak belirlenebilir. Burada bilinmesi gereken en önemli konu; medikal hastalıklar dışında kalça ve diz artroplastisi, pareziye neden olan akut spinal yaralanmalar, multipl büyük genel vücut travmaları, kanser nedeniyle yapılan abdominal ve pelvik cerrahilerde, VTE riskinin yüksek olduğu ve mutlaka koruyucu tedavi verilmesi gerekliliğidir. Caprini Risk Değerlendirme Modeli bu konuda kullanılan ölçütlerden biridir (Tablo 4). Bu modelin skorlama sisteminde hastalar, aldıkları puana göre çok düşük (0-1 puan), düşük (2 puan), orta (3-4 puan) ve yüksek (>5 puan) riskli olarak sınıflandırılır. ${ }^{[30]}$ Orta ve yüksek riskli olanlarda farmakolojik profilaksi, düşük riskli olanlarda öncelikle mekanik profilaksi düşünülmelidir. Caprini Risk Değerlendirme Modeli'nin doğruluk çalışmaları da yapılmıştır.

Rogers ve ark., genel cerrahi ve vasküler cerrahi hastalarında VTE risk skoru geliştirmişlerdir. Risk skoru 1-6 ise VTE riski düşük, 7-10 ise orta ve 10'un üzerinde yüksek risk olarak değerlendirilmektedir. ${ }^{[24]}$

Tablo 5'te gösterilen Maynard ve ark.'nın yaptığı skorlama sisteminde hastalar, düşük, orta ve yüksek riskli olarak sınıflandırılır. Orta ve yüksek risk gruplarına farmakolojik tedavi verilmesi önerilir. Bu, hem basit hem de daha anlaşılır bir skorlama sistemidir. ${ }^{[31]}$

İtalya Padua Üniversitesi'nin kullandığı VTE riskini tahmin skorlaması da basit bir yöntemdir. Kucher modeli esas alınarak düzenlenmiştir. ${ }^{[32]}$ Buna göre; toplam risk puanı 4 ve üzeri ise VTE riski yüksektir ve 
Tablo 4. Cerrahi hastalarda kullanılan Caprini risk değerlendirme modeli ${ }^{[30]}$

\begin{tabular}{|c|c|c|c|}
\hline 1 Puan & 2 Puan & 3 Puan & 5 Puan \\
\hline $\begin{array}{l}\text { - Yaş 41-60 } \\
\text { - Küçük cerrahi } \\
\text { - VKi >25 kg/m² } \\
\text { - Bacak şişmesi } \\
\text { - Variköz venler } \\
\text { - Gebelik/lohusalık } \\
\text { - Nedeni bilinmeyen ya da } \\
\text { tekrarlayan düşük öyküsü } \\
\text { - Oral kontraseptif ya da } \\
\text { hormon kullanımı } \\
\text { - Sepsis (<1 ay) } \\
\text { - Önemli akciğer hastalığı } \\
\text { (pnömoni dahil) (<1 ay) } \\
\text { - Anormal solunum testi } \\
\text { - Konjut miyokard infarktüsü kalp yetersizliği } \\
\text { (<1 ay) } \\
\text { - Inflamatuvar barsak hastalığı } \\
\text { öyküsü } \\
\text { - Yatağa bağımlı medikal hasta }\end{array}$ & $\begin{array}{l}\text { - Yaş 61-74 } \\
\text { - Artroskopik cerrahi } \\
\text { - Büyük açık cerrahi } \\
\text { - Laparoskopik cerrahi } \\
\text { (>45 dakika) } \\
\text { - Kanser } \\
\text { - Yatağa bağımlılık (>72 saat) } \\
\text { - Alçı nedeniyle immobilizasyon } \\
\text { - Santral venöz kateter }\end{array}$ & $\begin{array}{l}\text { - Yaş } 75 \text { ve üzeri } \\
\text { - VTE öyküsü } \\
\text { - VTE aile öyküsü } \\
\text { - Faktör V Leiden } \\
\text { - Protrombin } 20210 \mathrm{~A} \\
\text { - Lupus antikoagülanları } \\
\text { - Antikardiyolipin antikorları } \\
\text { - Yüksek homosistein } \\
\text { - Heparine bağlı trombositopeni } \\
\text { - Diğer trombofililer }\end{array}$ & $\begin{array}{l}\text { - Inme (>1 ay) } \\
\text { - Elektif alt ekstremite artroplastisi } \\
\text { - Kalça, pelvis ya da bacak kırığı } \\
\text { - Akut spinal kord yaralanması } \\
\text { (<1 ay) }\end{array}$ \\
\hline \multicolumn{4}{|c|}{$\begin{array}{l}\text { - Çok düşük risk (0-1 puan): erken mobilizasyon, yeterli hidratasyon. } \\
\text { - Düşük risk (2 puan): mekanik TP stratejisi. } \\
\text { - Orta risk (3-4 puan): kanama riski varsa mekanik TP, yoksa düşük doz SH (standart heparin) (2×1), ya da DMAH. } \\
\text { - Yüksek risk (>5 puan): kanama riski yoksa farmakolojik TP* + mekanik TP); } \\
\text { kanama riski varsa, mekanik TP, risk geçince farmakolojik TP'yi ekle. }\end{array}$} \\
\hline
\end{tabular}

* Düşük doz SH (3×1) ya da DMAH.

VKI, vücut kitle indeksi; $\mathrm{SH}$, standart heparin.

Tablo 5. Maynard VTE risk değerlendirilmesi ve koruyucu

DVT/PTE risk düzeyi Uygulanacak koruyucu tedavi

\section{Düşük risk:}

- Gözlemdeki hastalar (<48 saat), minör/ayaktan cerrahi müdahale

veya

- Yaş 50'nin üzeri ve diğer risk faktörleri yok

veya

- Zaten terapotik antikoagülan kullanımı var

\section{Orta risk:}

Çoğu medikal hasta/cerrahi hastaları

- Konjestif kalp yetmezliği

- Aktif inflamasyon

- Ileri yaş

- Variköz venler

- Kısmen immobil hasta

- Yüksek veya düşük risk olarak sınıflandırılamayan hastalar (daha yüksek risk için değerlendir)

Yüksek risk:

- Elektif kalça ve diz artroplastisi

- Akut spinal kord yaralanmaları (parezili)

- Multipl majör genel vücut travması

- Abdominal ve pelvik kanser cerrahisi
- Erken ambulasyon,

- Eğitim

\author{
Aşağıdaki farmakolojik tedavi seçeneklerinden birini seç*: \\ - Enoxaparin $40 \mathrm{mg} \mathrm{sc} / 24$ saat \\ - Enoxaparin $30 \mathrm{mg} \mathrm{sc} / 24$ saat (renal yetmezlik dozu) \\ - Heparin 5000 Ü sc/her 8 saatte bir \\ - Heparin her 12 saatte bir 5000 Ü sc (eğer $<50$ kg veya yaş >75) \\ Aynı zamanda (isteğe bağlı olarak) ekle: \\ - Kompresyon cihazı
}

Aşağıdaki farmakolojik tedavi seçeneklerinden birini seç*:
- Enoxaparin $40 \mathrm{mg} \mathrm{sc} / 24$ saat
- Enoxaparin $30 \mathrm{mg} \mathrm{sc} / 24$ saat (renal yetmezlik dozu)
- Heparin $5000 \mathrm{Ü} \mathrm{sc/her} 8$ saatte bir
(yalnızca son dönem renal hastalık için)
- Enoxaparin $30 \mathrm{mg} \mathrm{sc} / 12$ saatte bir (diz replasmanı için)
- Fondaparinux $2,5 \mathrm{mg} \mathrm{sc} / 24$ saatte bir
VE EKLE (zorunlu):
- Kompresyon cihazı

\section{VEYA}

Farmakolojik profilaksi yan etki riski VTE riskinden daha fazla ve/veya farmakolojik tedavi kontrendike ise:

- Kompresyon cihazları ile mekanik profilaksi

* Maynard ve ark., koruyucu tedavide, Tablo 5'te verdikleri düşük molekül ağırlıkı heparin preparatının örnek olduğunu ve diğer formüllere bir üstünlüğí olmadığını belirtmişlerdir. 
profilaksi verilmelidir. ${ }^{[33]}$ Hastanede yatmakta olan ve özellikle medikal tedavi alan hastalardaki risk faktörlerinin değerlendirilmesinde kullanılır.

Görüldüğü gibi, VTE riskini belirlemek için birbirine benzer birçok tahmin cetveli vardır. Bunlardan biri kullanılarak risk belirlenebilir ve uygun profilaksi tedavisi seçilebilir.

Majör ortopedik cerrahi olarak kabul edilen kalça kırıkları, diz ve kalça artroplastileri, yapılan çalışma ve kılavuzlarda üzerinde fikir birliğine varılan ve mutlaka tromboemboli profilaksisi verilmesi gereken yüksek risk grubundadır. Bunların yanında; paraziye neden olan akut spinal yaralanmalar ve multipl genel vücut travmalarına da mutlaka tromboemboli profilaksisi verilmelidir. Majör ortopedik cerrahi dışındaki diğer ortopedik operasyonlardaki VTE riski ve VTE profilaksi yöntemi, yapılan operasyon ve müdahaleye göre değişir (Tablo 6).

Tablo 6. Ortopedik operasyonlarda VTE profilaksisi

\begin{tabular}{|c|c|c|c|}
\hline Ortopedik operasyon & Çalışma & Kılavuzlar & $\begin{array}{l}\text { Klinik kanıt (Grade) } \\
\text { / Kanıt düzeyi }\end{array}$ \\
\hline \multirow[t]{4}{*}{ Diz artroskopisi } & $\operatorname{ACCP}(2012)^{[34]}$ & $\begin{array}{l}\text { Eski VTE öyküsü dışında VTE profilaksi } \\
\text { uygulanmasının, profilaksi uygulanmayanlara } \\
\text { üstünlüğü yoktur. }\end{array}$ & 2B \\
\hline & Krych ve ark. $(2015)^{[35]}$ & $\begin{array}{l}\text { VTE öyküsü, malignite ve iki veya daha fazla risk } \\
\text { faktörü olanlarda farmakolojik VTE profilaksisi } \\
\text { düşünülmeli. }\end{array}$ & Level 3 \\
\hline & NICE (2018) & - 90 dk ve üzeri total anestezi. & \\
\hline & & $\begin{array}{l}\text { - VTE riski kanama riskinden ağır basarsa } \\
14 \text { gün DMAH profilaksisi. }\end{array}$ & \\
\hline $\begin{array}{l}\text { İzole alt ekstremite ve diz distalini } \\
\text { ilgilendiren yaralanmalar }\end{array}$ & $\operatorname{ACCP}(2012)^{[34]}$ & $\begin{array}{l}\text { Farmokolojik VTE profilaksisinin, profilaksi } \\
\text { uygulanmayanlara üstünlügüü yoktur. }\end{array}$ & $2 C$ \\
\hline \multirow[t]{4}{*}{ İzole ayak ve ayak bileği cerrahisi } & Calder ve ark. $(2016)^{[36]}$ & Rutin kemoprofilaksi endikasyonu yoktur. & A/Level 2 \\
\hline & NICE (2018) & - Immobilizasyon gerekli ise... & \\
\hline & & - Toplamda 90 dk fazla süren anestezi. & \\
\hline & & $\begin{array}{l}\text {-VTE riski, kanama riskinden ağır basarsa } \\
\text { farmakolojik VTE profilaksisi düşünülmelidir. }\end{array}$ & \\
\hline \multirow[t]{4}{*}{ Alçı ile immobilizasyon } & Testroote ve ark. $(2014)^{[37]}$ & DMAH & Orta düzey kanıt \\
\hline & Zee ve ark. $(2017)^{[38]}$ & & \\
\hline & NICE (2018) & $\begin{array}{l}\text { - VTE riski kanama riskinden ağır basan } \\
\text { hastalarda DMAH veya fondaparinux. }\end{array}$ & \\
\hline & & $\begin{array}{l}\text { - Profilaksinin } 42 \text { gün sonra kesilmesi } \\
\text { düşünülmelidir. }\end{array}$ & \\
\hline \multirow[t]{2}{*}{ Aşil tendon yırtığı } & Patel ve ark. $(2012)^{[39]}$ & Rutin VTE profilaksisi gereksiz olabilir. & Level 3 \\
\hline & Calder ve ark. $(2016)^{[36]}$ & Rutin mekanik anti-VTE metodların kullanımı. & B / Level 2 \\
\hline \multirow[t]{3}{*}{ Üst ekstremite cerrahisi } & NICE (2018) & $\begin{array}{l}\text { Lokal veya rejyonel anestezi uygulanan hastalarda } \\
\text { VTE profilaksisine genellikle gerek yoktur. }\end{array}$ & - \\
\hline & & $\begin{array}{l}\text { - Genel anestezi altındaki sürenin } 90 \text { dk fazla } \\
\text { olması halinde ve }\end{array}$ & \\
\hline & & $\begin{array}{l}\text { - Operasyon nedeniyle zor mobilize olanlarda } \\
\text { VTE profilaksisi düşünülebilir. }\end{array}$ & \\
\hline \multirow[t]{2}{*}{ Omuz artroplastisi } & Day ve ark. $(2015)^{[40]}$ & - Aspirin ile kombine mekanik profilaksi. & Epidemiyolojik çalışma \\
\hline & & $\begin{array}{l}\text {-VTE riski bulunanlarda aspirin dışı } \\
\text { farmakolojik tedavi verilebilir. }\end{array}$ & \\
\hline
\end{tabular}




\section{VTE VE KANAMA RISKLERI AÇISINDAN PROFILAKSI YÖNTEMLERI}

Profilaksi yönteminin seçiminde, VTE risk düzeyi, hastanın klinik koşulları, kanama riski, seçilecek yöntemin komplikasyonları, hastanın tercihi ve hastanın yönteme uyumu dikkate alınmalıdır. TP, mekanik ve farmakolojik profilaksi olmak üzere ikiye ayrilır.

\section{Mekanik Profilaksi}

Basınçlı elastik çorap ve pnömatik kompresyon cihazlarıdır. Bu cihazlar, kanı yüzeyel venlerden derin venlere yönlendirerek, derin venlerdeki kan hacmini ve akım hızını arttırmak yolu ile venöz stazı azaltır. ${ }^{[41]}$ Bu yöntemler, asemptomatik DVT oluşmasını \%5060 oranında azaltır. Fakat, PTE oluşmasını önlemede bu oranda başarılı değildir. Mekanik yöntemlerin, hastanın hareketlerini kısıtlamak ve yaşam konforunu bozmak, cilt sorunları oluşturmak gibi sakıncaları vardır. ${ }^{[41,42]}$ Bu nedenle, yöntem seçiminde hasta uyumu dikkate alınmalı, hastalar yeterince bilgilendirilmeli ve kullanım konusunda eğitilmelidirler.

\section{Farmakolojik Profilaksi}

VTE riski orta ve yüksek hastalarda en güçlü ve etkin TP stratejisi, antikoagülan ilaçların profilaksi dozları ile yapılan farmakolojik profilaksidir. Tablo 7'de gösterilen farmakolojik profilaksi ajanları, hasta uyumu ve risk faktörleri göz önüne alınarak kullanılabilir. Son zamanlarda aspirinin de etkin profilakside kullanılabileceği gösterilmiştir. ${ }^{[33,44]}$ Düşük doz aspirin ile yüksek doz aspirinin VTE profilaksisinde anlamlı bir farkı olmadığı için, yan etki ve risk faktörleri göz önüne alındığında, profilakside düşük doz aspirin önerilmektedir (Tablo 7). ${ }^{[4]}$ Profilaksi dozunda dahi olsalar, antikoagülanların majör ya da minör kanamaya neden olabilecekleri unutulmamalıdır. Altıntaş ve ark.'nın yaptığı çalışmada, majör ortopedik cerrahi uygulanan hastalarda farmakolojik profilaksi sonrası $\% 0,6$ hastada yara yeri hematomu gelişmiştir. Ayrıca, \%0,3 intraserebral kanama, $\% 4,5$ hafif kanama, \%0,1 trombositopeni geliştiği görülmüş̧ür. ${ }^{[11]}$

Tablo 7. VTE'nin farmakolojik tromboprofilaksisinde kullanılan ilaçlar ve dozları

\begin{tabular}{|c|c|c|c|}
\hline Antikoagülanlar & $\begin{array}{l}\text { Medikal } \\
\text { hastada }\end{array}$ & $\begin{array}{l}\text { Non-ortopedik } \\
\text { cerrahi hastasında }\end{array}$ & $\begin{array}{l}\text { Ortopedik cerrahi } \\
\text { hastasında (TKA, TDA) }\end{array}$ \\
\hline Enoksaparin & 40 mg/gün, cilt altı & $40 \mathrm{mg} /$ gün, cilt altı & $40 \mathrm{mg} /$ gün cilt altı \\
\hline Dalteparin & 5000 U/gün, cilt altı & $5000 \mathrm{U} /$ gün, cilt altı & $5000 \mathrm{U} /$ gün, cilt altı \\
\hline Nadroparin & $3400 \mathrm{IU} /$ gün, cilt altı & 3400 IU/gün, cilt altı & $3400 \mathrm{IU} /$ gün, cilt altı \\
\hline Standart heparin & $\begin{array}{l}5000 \mathrm{U} \\
\cdot 2 \times 1 / \text { gün, cilt altı } \\
\cdot 3 \times 1 * / \text { gün, cilt altı } \\
\left({ }^{*} \text { yüksek riskli olgularda) }\right.\end{array}$ & $\begin{array}{l}5000 \mathrm{U} \\
\cdot 2 \times 1 / \text { gün, cilt altı } \\
\cdot 3 \times 1 * / \text { gün, cilt altı } \\
\text { ( }{ }^{*} \text { yüksek riskli olgularda) }\end{array}$ & $\begin{array}{l}5000 \mathrm{U} \\
\cdot 2 \times 1 / \text { gün, cilt altı } \\
\cdot 3 \times 1{ }^{*} / \text { gün, cilt altı } \\
\left({ }^{*} \text { yüksek riskli olgularda) }\right.\end{array}$ \\
\hline Varfarin & Kullanılmaz & Kullanılmaz & Tek başına kullanılmaz. \\
\hline Fondaparinuks & $\begin{array}{l}2,5 \mathrm{mg} / \text { gün, cilt altı* } \\
\text { ( }{ }^{*} \text { ülkemizde henüz ruhsatı yok) }\end{array}$ & Kullanılmaz & 2,5 mg/gün, cilt altı \\
\hline Rivaroksaban & $\begin{array}{l}\text { Kullanılmaz } \\
\text { (DMAH'lar kadar etkili fakat } \\
\text { majör kanama yüksek) }\end{array}$ & Çalışması yok & 10 mg/gün, oral \\
\hline Dabigatran & Çalışması yok & Çalışması yok & $110 \mathrm{mg} \times 2$, oral \\
\hline Apiksaban & $\begin{array}{l}\text { Kullanılmaz } \\
\text { (DMAH'lar kadar etkili fakat } \\
\text { majör kanama yüksek) }\end{array}$ & Çalışması yok & $2,5 \mathrm{mg} \times 2$, oral \\
\hline Asetilsalisilik asit & $\begin{array}{l}\text { Düşük doz (75-150 mg/gün), oral } \\
\text { Orta doz (160-325 mg/gün), oral }\end{array}$ & $\begin{array}{l}\text { Düşük doz (75-150 mg/gün), oral } \\
\text { Orta doz (160-325 mg/gün), oral }\end{array}$ & $\begin{array}{l}\text { Düşük doz ( } 2 \times 81 \mathrm{mg} / \text { gün), oral } \\
\text { Yüksek doz ( } 2 \times 325 \mathrm{mg} / \text { gün), oral } \\
\text { (düşük doz ve yüksek doz arasında } \\
\text { anlamlı fark yok ama yan etki } \\
\text { açısından düşük doz önerilir) }\end{array}$ \\
\hline
\end{tabular}

VTE, venöz tromboembolizm; TKA, total kalça artroplastisi; TDA, total diz artroplasitisi 


\section{SONUÇ}

Majör ortopedik cerrahiler olarak bilinen, kalça kırığı, diz ve kalça artroplastileri, yüksek VTE risk grubuna girmektedir ve bu hastalara, kanama riski de göz önünde bulundurularak uygun TP tedavisi uygulanmalıdır. Diğer ortopedik cerrahilerde, özellikle hastanın mobilizasyonu, anestezi türü ve süresi ve diğer risk faktörlerinin varlığı göz önüne alınarak profilaksi uygulanabilir. DVT ve fatal olan PE'den korunmanın yolu, hastaların VTE risk faktörleri ve kanama riskleri açısından iyi değerlendirilmesi sonucunda hastaya özgü profilaksi tedavisinin uygulanmasından geçer.

\section{KAYNAKLAR}

1. Cushman M. Epidemiology and risk factors for venous thrombosis. Semin Hematol 2007;44(2):62-9. Crossref

2. Cohen AT, Tapson VF, Bergmann JF, Goldhaber SZ, Kakkar AK, Deslandes B, Huang W, Zayaruzny M, Emery L, Anderson FA Jr; ENDORSE Investigators.. Venous thromboembolism risk and prophylaxis in the acute hospital care setting (ENDORSE study): a multinational cross-sectional study. Lancet 2008;371(9610):387-94. Crossref

3. Sandler DA, Martin JF. Autopsy proven pulmonary embolism in hospital patients: are we detecting enough deep vein thrombosis? J R Soc Med 1989;82(4):203-5. Crossref

4. Geerts WH, Pineo GF, Heit JA, Bergqvist D, Lassen MR, Colwell CW, Ray JG. Prevention of venous thromboembolism: the Seventh ACCP Conference on Antithrombotic and Thrombolytic Therapy. Chest 2004;126(3):338S-400S. Crossref

5. White RH. The epidemiology of venous thromboembolism. Circulation 2003;107(23 suppl 1): I-4-8. Crossref

6. Geerts $\mathrm{WH}$, Bergqvist D, Pineo GF, Heit JA, Samama CM, Lassen MR, Colwell CW.. Prevention of venous thromboembolism: American College of Chest Physicians evidence-based clinical practice guidelines (8th Edition). Chest 2008;133(6):381S-453S. Crossref

7. Lindblad B, Eriksson A, Bergqvist D. Autopsy-verified pulmonary embolism in a surgical department: analysis of the period from 1951 to 1988. BrJ Surg 1991;78(7):849-52. Crossref

8. Stein PD, HenryJW. Prevalence of acute pulmonary embolism among patients in a general hospital and at autopsy. Chest 1995;108(4):978-81. Crossref

9. Demir M, Erdemli B, Kurtoğlu M, Öngen G, editörler. Ulusal Venöz Tromboembolizm Profilaksi ve Tedavi Kılavuzu -2010. İstanbul: GüVen Platformu, Cortex Illetişim; 2010.

10. Anderson FA Jr, Spencer FA. Risk factors for venous thromboembolism. Circulation 2003;107(23 Suppl 1): I-916. Crossref

11. Altıntaş F, Gürbüz H, Erdemli B, Atilla B, Ustaoğlu RG, Öziç U, Şavk Ö, Bayram H, Memik R, Akgün I, Göğüş A, Pestilci F, Konal A, Argün M, Öztürk I, Dabak N, Bilgen ÖF, Serin E, Önder Ç, Şimşek A, Tözün R, Kınık H. Majör ortopedik cerrahilerde venöz tromboemboli profilaksisi: Çok merkezli, prospektif, gözlem çalışması. Acta Orthop Traumatol Turc 2008;42(5):322-7. Crossref
12. Ongen G, Yılmaz A, Cirak AK, Ersoy CY, Erden F, Altıntaş F, Yıldırım C, Güven H, Demir A, Kaynar L, Bastacı N, Demirtaş N.. Venous thromboembolism risk and thromboprophylaxis among hospitalized patients: data from the Turkish arm of the ENDORSE study. Clin Appl Thromb Hemost 2011;17(5):539-45. Crossref

13. National Clinical Guideline Centre - Acute and Chronic Conditions (UK). National Institute for Health and Clinical Excellence: Guidance. Reducing the risk of venous thromboembolism (deep vein thrombosis and pulmonary embolism) in patients admitted to hospital. London: Royal College of Physicians (UK); 2010. PMID: 23346611

14. Samama MM, Cohen AT, Darmon JY, Desjardins L, Eldor A, Janbon C, Leizorovicz A, Nguyen H, Olsson CG, Turpie AG, Weisslinger N.. A comparison of enoxaparin with placebo for the prevention of venous thromboembolism in acutely ill medical patients. Prophylaxis in Medical Patients with Enoxaparin Study Group. New Engl J Med 1999;341(11):793800. Crossref

15. Erdemli B, Başarır K. Venöz Tromboemboli. Turkiye Klinikleri J Orthop \& Traumatol-Special Topics 2010;3(3):86-92.

16. Nakao S, Takata S, Uemura $\mathrm{H}$, Nakano $\mathrm{S}$, Egawa $\mathrm{H}$, Kawasaki Y, Kashihara M, Yasui N.. Early ambulation after total knee arthroplasty prevents patients with osteoarthritis and rheumatoid arthritis from developing postoperative higher levels of D-dimer. J Med Invest 2010;57(1-2):146-51. Crossref

17. Decousus H, Tapson VF, Bergmann JF, Chong BH, Froehlich JB, Kakkar AK, Merli GJ, Monreal M, Nakamura M, Pavanello R, Pini M, Piovella F, Spencer FA, Spyropoulos AC, Turpie AG, Zotz RB, Fitzgerald G, Anderson FA; IMPROVE Investigators.. Factors at admission associated with bleeding risk in medical patients: findings from the IMPROVE investigators. Chest 2011;139(1):69-79. Crossref

18. Hull RD, Schellong SM, Tapson VF, Monreal M, Samama MM, Nicol P, Vicaut E, Turpie AG, Yusen RD; EXCLAIM (Extended Prophylaxis for Venous ThromboEmbolism in Acutely III Medical Patients With Prolonged Immobilization) study.. Extended-duration venous thromboembolism prophylaxis in acutely ill medical patients with recently reduced mobility: a randomized trial. Ann Intern Med 2010;153(1):8-18. Crossref

19. Kahn SR, Lim W, Dunn AS, Cushman M, Dentali F, Akl EA, Cook DJ, Balekian AA, Klein RC, Le H, Schulman S, Murad MH.. Prevention of VTE in nonsurgical patients: antithrombotic therapy and prevention of thrombosis, 9th ed: American College of Chest Physicians evidence-based clinical practice guidelines. Chest 2012;141(2):e195S-226S. Crossref

20. Wilson D, Cooke EA, McNally MA, Wilson HK, Yeates A, Mollan RA.. Changes in coagulability as measured by thrombelastography following surgery for proximal femoral fracture. Injury 2001;32(10):765-70. Crossref

21. Wilson D, Cooke EA, McNally MA, Wilson HK, Yeates A, Mollan RAB. Altered venous function and deep venous thrombosis following proximal femoral fracture. Injury 2002;33(1):33-9. Crossref

22. White RH, Romano PS, Zhou H, Rodrigo J, Bargar W. Incidence and time course of thromboembolic outcomes following total hip or knee arthroplasty. Arch Intern Med 1998;158(14):1525-31. Crossref

23. Planes A, Vochelle N, Darmon JY, Fagola M, Bellaud M, Huet Y.. Risk of deep-venous thrombosis after hospital discharge in patients having undergone total hip replacement: doubleblind randomised comparison of enoxaparin versus placebo. Lancet 1996;348(9022):224-8. Crossref 
24. Roger VL, Go AS, Lloyd-Jones DM, Benjamin EJ, Berry JD, Borden WB, Bravata DM, Dai S, Ford ES, Fox CS, Fullerton HJ, Gillespie C, Hailpern SM, Heit JA, Howard VJ, Kissela BM, Kittner SJ, Lackland DT, Lichtman JH, Lisabeth LD, Makuc DM, Marcus GM, Marelli A, Matchar DB, Moy CS, Mozaffarian D, Mussolino ME, Nichol G, Paynter NP, Soliman EZ, Sorlie PD, Sotoodehnia N, Turan TN, Virani SS, Wong ND, Woo D, Turner MB; American Heart Association Statistics Committee and Stroke Statistics Subcommittee. Heart disease and stroke statistics-2012 Update. A report from the American Heart Association. Circulation 2012;125(1):e2-220.

25. Network SIGN, Scottish Intercollegiate Guidelines Network. SIGN, 2010. https://www.sign.ac.uk/sign-122-preventionand-management-of-venous-thromboembolism.html

26. Flevas DA, Megaloikonomos PD, Dimopoulos L, Mitsiokapa E, Koulouvaris P, Mavrogenis AF.. Thromboembolism prophylaxis in orthopaedics: an update. EFORT Open Rev 2018;3(4):136-48. Crossref

27. Nam D, Nunley RM, Johnson SR, Keeney JA, Clohisy JC, Barrack RL.. Thromboembolism prophylaxis in hip arthroplasty: routine and high risk patients. J Arthroplasty 2015;30(12):2299-303. Crossref

28. Della Valle AG, Khakharia S, Glueck CJ, Taveras N, Wang $P$, Fontaine RN, Salvati EA. VKORC1 variant genotypes influence warfarin response in patients undergoing total joint arthroplasty: a pilot study. Clin Orthop Relat Res 2009;467(7):1773-80. Crossref

29. Vulcano E, Gesell M, Esposito A, Ma Y, Memtsoudis SG, Gonzalez Della Valle A.. Aspirin for elective hip and knee arthroplasty: a multimodal thromboprophylaxis protocol. Int Orthop 2012;36(10):1995-2002. Crossref

30. Caprini JA. Thrombosis risk assessment as a guide to quality patient care. Disease-a-Month 2005;51(2-3):70-8. Crossref

31. Maynard G, Stein J. Designing and implementing effective venous thromboembolism prevention protocols: lessons from collaborative efforts. J Thromb Thrombolysis 2010;29(2):159-66. Crossref

32. Kucher $\mathrm{N}$, Koo S, Quiroz R, Cooper JM, Paterno MD, Soukonnikov B, Goldhaber SZ.. Electronic alerts to prevent venous thromboembolism among hospitalized patients. New Engl J Med 2005;352(10):969-77. Crossref

33. Barbar S, Noventa F, Rossetto V, Ferrari A, Brandolin B, Perlati M, De Bon E, Tormene D, Pagnan A, Prandoni P.. A risk assessment model for the identification of hospitalized medical patients at risk for venous thromboembolism: the Padua Prediction Score. J Thrombosis Haemostasis 2010;8(11):2450-7. Crossref

34. Falck-Ytter Y, Francis CW, Johanson NA, Curley C, Dahl OE, Schulman S, Ortel TL, Pauker SG, Colwell CW Jr.. Prevention of VTE in orthopedic surgery patients: antithrombotic therapy and prevention of thrombosis: American College of Chest Physicians evidence-based clinical practice guidelines. Chest 2012;141(2 Suppl):e278S-325S. Crossref
35. Krych AJ, Sousa PL, Morgan JA, Levy BA, Stuart MJ, Dahm DL.. Incidence and risk factor analysis of symptomatic venous thromboembolism after knee arthroscopy. Arthroscopy 2015;31(11):2112-8. Crossref

36. Calder JD, Freeman R, Domeij-Arverud E, van Dijk CN, Ackermann PW.. Meta-analysis and suggested guidelines for prevention of venous thromboembolism (VTE) in foot and ankle surgery. Knee Surg Sports Traumatol Arthrosc 2016;24(4):1409-20. Crossref

37. Testroote M, Stigter WA, Janssen L, Janzing HM.. Low molecular weight heparin for prevention of venous thromboembolism in patients with lower-leg immobilization. Cochrane Database Syst Rev 2014;(4):CD006681. Crossref

38. Zee AA, van Lieshout $K$, van der Heide $M$, Janssen $L$, Janzing HM.. Low molecular weight heparin for prevention of venous thromboembolism in patients with lower-limb immobilization. Cochrane Database Syst Rev 2017;8:CD006681. Crossref

39. Patel A, Ogawa B, Charlton T, Thordarson D. Incidence of deep vein thrombosis and pulmonary embolism after Achilles tendon rupture. Clin Orthop Relat Res 2012;470(1):270-4. Crossref

40. Day JS, Ramsey ML, Lau E, Williams GR.. Risk of venous thromboembolism after shoulder arthroplasty in the Medicare population. J Shoulder Elbow Surg 2015;24(1):98105. Crossref

41. Benkö T, Cooke EA, McNally MA, Mollan RAB. Graduated compression stockings: knee length or thigh length. Clin Orthop Relat Res 2001;383:197-203. Crossref

42. Guyatt GH, Norris SL, Schulman S, Hirsh J, Eckman MH, Akl EA, Crowther M, Vandvik PO, Eikelboom JW, McDonagh MS, Lewis SZ, Gutterman DD, Cook DJ, Schünemann HJ.. Methodology for the development of antithrombotic therapy and prevention of thrombosis guidelines: Antithrombotic Therapy and Prevention of Thrombosis: American College of Chest Physicians Evidence-Based Clinical Practice Guidelines. Chest 2012;141(2):53S-70S. Crossref

43. Azboy I, Barrack R, Thomas AM, Haddad FS, Parvizi J.. Aspirin and the prevention of venous thromboembolism following total joint arthroplasty: commonly asked questions. Bone Joint J 2017;99-B(11):1420-30. Crossref

44. Parvizi J, Huang R, Restrepo C, Chen AF, Austin MS, Hozack WJ, LonnerJH. Low-dose aspirin is effective chemoprophylaxis against clinically important venous thromboembolism following total joint arthroplasty: a preliminary analysis. J Bone Joint Surg Am 2017;99(2):91-8. Crossref 